\title{
STUDY ON BIOLOGICAL ACTIVITY OF Litsea monopetala FROM PANCHTHAR DISTRICT OF NEPAL
}

\author{
Subash Khanal, Bishan Datt Bhatt ${ }^{*}$ \\ Department of Chemistry, Tri-Chandra Multiple Campus, Tribhuvan University, Kathmandu, Nepal \\ *Corresponding author: bishan.bhatt@trc.tu.edu.np, bdbhatta@gmail.com
}

(Received: April 03, 2019; Revised: October 13, 2020; Accepted: October 15, 2020)

\begin{abstract}
The Panchthar, a hilly district of Eastern Nepal, has several medicinal plants which are used by indegenous people for the treatments of different diseases. In the present work, phytochemical and biological activities of hexane, ethyl acetate, acetone, and methanol extracts of Litsea monopetala leaves from the Pachthar district were analyzed. The phytochemical screening demonstrated the presence of major secondary metabolites like flavonoids, alkaloids, terpenoids, polyphenols, glycosides, and proteins. The antibacterial activity was estimated by the disc diffusion method against Bacillus substilus and Escherichia coli. The result showed that ethyl acetate extract exhibit the highest zone of inhibition (ZOI) value of 18 $\mathrm{mm} /$ disc. Acetone extract also showed significant antibacterial activity at the concentration of $100 \mathrm{mg} / \mathrm{mL}$. Antioxidant activity from DPPH radical scavenging assay displayed the inhibitory concentration $\left(\mathrm{IC}_{50}\right)$ values of dried methanol and acetone extracts were $30.74 \mu \mathrm{g} / \mathrm{mL}$ and $202.86 \mu \mathrm{g} / \mathrm{mL}$, respectively. The methanol extract has the highest total phenolic content of $360.14 \mathrm{mg} \mathrm{GAE} / \mathrm{g}$ extract and the highest total flavonoid content of $27.13 \mathrm{mg}$ QE/g extract. The present study revealed that Litsea monopetala plant from the Panchthar district is a source of several bioactive substances and can be used in several drugs formulation.
\end{abstract}

Keywords: Litsea monopetala, Phytochemicals, Flavonoids, Antibacterial activity, Antioxidant activity.

\section{INTRODUCTION}

Numerous medically important chemical compounds since ancient times, and a large number of modern drugs have been extracted from the natural sources. Traditional medicine uses many chemical substances derived from the natural products (Ramamurthy et al., 2013). According to WHO, about 65 to $80 \%$ of the world's population in the developing countries depend essentially on the plant extracts as folk medicines for their primary health, driven by poor economic conditions and reduced access to modern medicine (Awoyemi et al., 2012). People have been using plant and plant products since prehistoric period in Nepal to heal various diseases without knowing their chemical constituents and biological activities (Aryal et al., 2016; Gewali, 2008). The medicinal values of varieties of Nepalese plants from different localities have been reported in previous studies (Rajbhandari \& Lindequist, 2020; Joshi \& Bashyal, 2018, Subba \& Thapa, 2018). However, few works have been reported on the medicinal plants from the Panchthar district of Nepal (Bhandari et al., 2020; Gautam, 2011).

Panchthar district of Nepal is one of the most important natural storehouses of medicinal plants owing to its geographical diversity, variations in topography, altitude, climatic gradients, and biological resources of flora and fauna (Gautam, 2011). A recent review on the ethnomedicinal study of the Chyangthapu-Phalaicha biological sub-corridor of the northern part of Panchthar district located in the Kangchenjunga Landscape indicated that the area has significant medicinal plants and traditional knowledge associated with it (Bhandari et al., 2020). The use of the medicinal plants in the area indicates the need for their cultivation, processing and phytochemical investigation, especially for those with high ethnobotanical indices. In this context, present work was focused to study on biological efficacies of leaf part of Litsea monopetala (Roxb.) plant of Panchthar district.

Litsea monopetala (Roxb.) Pers. tree can grow up to the height of 18 meters and has leaves of $7.5-23 \mathrm{~cm}$ dimension with long, elliptic-oblong shape, usually rounded at both ends, and pubescent beneath (Hasan et $a l ., 2016)$. The tree commonly found in Nepal and other Asian countries, is known as kutmiro in Nepali Considered as the Ayurvedic plant, its barkis known to have stimulant, astringent, spasmolytic, and antidiarrheal property. The roots of this plant are utilized to heal pains, bruises, and contusions (Hasan et al., 2014). Traditionally, the plant has been used to treatment ailments like bone fracture in cattle, diarrhea, dysentery, jaundice, and stomachache. The plant has shown stimulant, analgesic, and antiseptic properties as well (Hasan et al., 2016).

The phytoconstituents found in Litsea monopetala have been reported as caryophyllene oxide, humulene oxide, capric acid, and myristic acid (Wang et al., 2016). present work aimed to study the biological efficacy of Litsea monopetala by knowing the phytochemicals, total phenolic content, total flavonoid content, antimicrobial activity, and antioxidant properties of the acetone and methanol extracts of the plant leaves. 


\section{MATERIALS AND METHODS}

\section{Selection of plant material}

Litsea monopetala plant selected consulting with the local plant users, healers, and old persons of Kummayak Rural Municipality, Panchthar district of Nepal who have indigenous knowledge about this plant and have been using for many years for the treatment of different diseases.

\section{Extract preparation}

The leaves of Litsea monopetala were collected, shade dried and ground to powder form which was used for the extraction. The plant extract was prepared by soxhlet extraction using successive solvents; hexane, ethyl acetate, acetone, and methanol, based on their increasing polarity, and each extract was concentrated using a rotatory evaporator.

\section{Phytochemical analysis}

Freshly prepared extracts were subjected to standard phytochemical analysis to assess the presence of phytoconstituents like alkaloids, phenols, flavonoids, glycosides, coumarins, tannins, saponins, steroids, terpenoids, proteins, and carbohydrate. The phytochemicals screening was performed following the procedure of Dhote et al. (2015).

\section{Antioxidant activity}

Free radical scavenging activity was determined by using 1,1-diphenyl-2-picryl hydrazyl radical (DPPH), a stable free radical purple in color. When free radical scavengers were added, DPPH was reduced and its color changed to yellow based on the efficacy of antioxidants (Jamuna et al., 2012). Scavenging of DPPH free radical indicates the antioxidants potential of the extract which is effective in prevention, interception, and repair mechanism against injury in the biological system. The following formula was used to calculate the percentage of radical scavenging activity (Ferdous et al., 2018), as given in equation (1).

$$
\text { Radical Scavening }(\%)=\frac{\mathrm{A}_{0}-\mathrm{A}_{1}}{\mathrm{~A}_{0}} \times 100
$$

Where, $A_{0}$ is the absorbance of the control and $A_{1}$ is the absorbance of the sample extract.

\section{Radical Scavenging}

Concentrations of $20,40,60,80$, and $100 \mu \mathrm{g} / \mathrm{mL}$ test sample were prepared, and their absorbance was measured in a UV-visible spectrophotometer at the wave length of $517 \mathrm{~nm}$. Ascorbic acid solution of the same concentrations was prepared as a standard and their absorbances were taken in the same wavelength. A calibration curve was prepared. Percent radical scavenging activity by sample treatment was determined by comparison with the methanol treated control group. The ascorbic acid was used as a positive control.

\section{Determination of total phenolic content (TPC)}

Since the phenolic compounds possess high free radical scavenging properties, they exhibit high antioxidant properties. Therefore, it is obvious that extract containing a higher amount of polyphenols possesses a greater antioxidant activity. The TPC in plant extract was estimated by using Folin-Ciocalteu reagent (FCR) colorimetric method based upon oxidation-reduction reaction as described by Waterhouse (2012). For the purpose, different concentrations of test samples were prepared with gallic acid as standard and absorbance was measured using spectrophotometer at $760 \mathrm{~nm}$ against blank for each concentration. The TPC in extract was expressed as milligrams of gallic acid equivalent per gram of dry weight (mg GAE/g) of extract, which was calculated in all the extracts separately using the following formula, as shown in the equation (2).

$$
\mathrm{C}=\frac{\mathrm{cV}}{\mathrm{m}}
$$

Where, $\mathrm{C}=$ Total phenolic content in $\mathrm{mg} / \mathrm{g}$, in gallic acid equivalent $(\mathrm{GAE}) ; \mathrm{c}=$ Concentration of gallic acid established from the calibration curve in $\mathrm{mg} / \mathrm{mL} ; \mathrm{V}=$ Volume of extract in $\mathrm{mL}$, and $\mathrm{m}=$ Mass of plant extract.

\section{Determination of total flavonoid content (TFC)}

Aluminum chloride colorimetric assay was used for the estimation of total flavonoid present in the methanol extract of the plant, according to the standard procedure given by Kalita et al. (2013). This procedure involves quercetin as standard. Different concentrations of test samples of $20,40,60,80$, and $100 \mu \mathrm{g} / \mathrm{mL}$ were prepared. Absorbance for each concentration of the extract was measured at $510 \mathrm{~nm}$ spectrophotometrically against blank for each concentration. The total flavonoid content in extract was expressed as milligrams of quercetin equivalent per gram of dry weight $(\mathrm{mg} \mathrm{QE} / \mathrm{g}$ ) of extract, which was calculated in all the extracts separately using the formula, as shown in the equation (3).

$$
\mathrm{C}_{\mathrm{TF}}=\frac{\mathrm{c}_{\mathrm{Q}} \mathrm{V}}{\mathrm{m}}
$$

Where, $\mathrm{C}_{\mathrm{TF}}=$ total flavonoid content in $\mathrm{mg} / \mathrm{g}$, in quercetin equivalent $(\mathrm{QE}) ; \quad \mathrm{c}_{\mathrm{Q}}=$ concentration of quercetin established from the calibration curve in $\mathrm{mg} / \mathrm{mL} ; \mathrm{V}=$ volume of extract in $\mathrm{mL}$, and $\mathrm{m}=$ mass of plant extract.

\section{Antimicrobial assay}

The effect of the crude plant extract or fraction at fixed dose level in two different types of bacteria was studied. Agar well diffusion assay was performed to screen and evaluate the antibacterial activity of the crude plant 
extracts. Inhibition of the bacterial growth was tested by the agar disc diffusion method measuringthe zone of inhibition (Cavalieri et al., 2005). Bacillus subtilis-ATCC 6051 (Gram-positive bacteria) and Escherichia coliATCC 25922 (Gram-negative bacteria) were the tested bacterial species.

\section{RESULTS AND DISCUSSION}

\section{Phytochemical analysis}

The presence or absence of the main chemical constituents in the plant extracts was confirmed by the color reaction using specific reagents, and the results are summarized in Table 1.

Table 1. Phytochemical screening of different leaf extracts of Litsea monopetala

\begin{tabular}{lcccc}
\hline Groups of Compounds & HE & EE & AE & ME \\
\hline Basic Alkaloids & - & - & + & + \\
Flavonoids & - & - & + & + \\
Coumarins & - & - & + & + \\
Saponins & - & + & + & + \\
Polyphenols & + & + & + & + \\
Terpenoids & + & - & + & + \\
Cardiac Glycosides & + & - & - & + \\
Proteins & - & - & + & + \\
Carbohydrate & - & - & + & + \\
\hline
\end{tabular}

$(+)$ indicates present and $(-)$ indicates absent, $H E=$ hexane extract, $E E=$ ethyl acetate extract, $A E=$ acetone extract, $M E=$ methanol extract

These results show the presence of most of the phytochemicals in the extracts of acetone and methanol because acetone and methanol are more polar solvents than ethyl acetate and hexane. The amount of phytochemicals present in the plant extracts depend also upon climatic, geographical, and altitudinal variations. These factors determine the amount of secondary metabolites persistence during the adaptation phenomenon. Due to these reasons, the phytochemicals reported in this work may be slightly different from the data present in the literature of the selected plant.

\section{Antioxidant activity}

The $\mathrm{IC}_{50}$ value of each extract and ascorbic acid was calculated. The percentage radical scavenging activity of different extracts of Litsea monopetala leaves and ascorbic acid at different concentrations were calculated and the results are tabulated in Table 2 .

The recorded absorbance at various concentrations is depicted in Table 3 . The calibration curve was constructed by measuring the absorbance of ascorbic acid to calculate the $\mathrm{IC}_{50}$ value, which was found to be $21.23 \mu \mathrm{g} / \mathrm{mL}$. The absorbance of control was 0.6964 .
The percentage of radical scavenging activity (RSA) against the concentrations of the methanol and acetone extracts are shown in Figs. 1 and 2, respectively. The RSA value of the methanol extract was very close to the ascorbic acid (Fig. 1), however, the value of the acetone extract was not close to the ascorbic acid (Fig. 2), yet it showed some antioxidant property. Besides, the $\mathrm{IC}_{50}$ values of the methanol and acetone extracts of Litsea monopetala plant were found 30.74 and $202.86 \mu \mathrm{g} / \mathrm{mL}$, respectively. The $\mathrm{IC}_{50}$ value in the methanol extract was very close to the standard ascorbic acid $(21.23 \mu \mathrm{g} / \mathrm{mL})$. These results reflected that the methanol extract of the plant possesses high antioxidant activity compared to the acetone extract.

Table 2. Percentage of radical scavenging of leaf extracts of Litsea monopetala at different concentrations

\begin{tabular}{lccccc}
\hline $\begin{array}{l}\text { Conc. } \\
(\boldsymbol{\mu g} / \mathbf{m L})\end{array}$ & $\mathbf{2 0}$ & $\mathbf{4 0}$ & $\mathbf{6 0}$ & $\mathbf{8 0}$ & $\mathbf{1 1 0}$ \\
\cline { 2 - 6 } $\begin{array}{l}\text { Methanol } \\
\text { extract }\end{array}$ & 64.33 & 68.06 & 80.70 & 82.28 & 89.46 \\
\hline $\begin{array}{l}\text { Acetone } \\
\text { extract }\end{array}$ & 09.76 & 10.62 & 15.06 & 22.92 & 24.50 \\
\hline $\begin{array}{l}\text { Ascorbic } \\
\text { acid }\end{array}$ & 71.23 & 85.98 & 88.94 & 95.65 & 98.49 \\
\hline
\end{tabular}

Table 3. Absorbance values of different concentrations of leaf extract of of Litsea monopetala for antioxidant property

\begin{tabular}{lccccc}
\hline \multirow{2}{*}{ Extracts } & \multicolumn{5}{c}{ Absorptions at concentrations $(\mu \mathrm{g} / \mathrm{mL})$} \\
\cline { 2 - 6 } & 20 & 40 & 60 & 80 & 100 \\
Acetone & 0.017 & 0.059 & 0.079 & 0.099 & 0.119 \\
Methanol & 0.057 & 0.075 & 0.169 & 0.093 & 0.122 \\
\hline
\end{tabular}

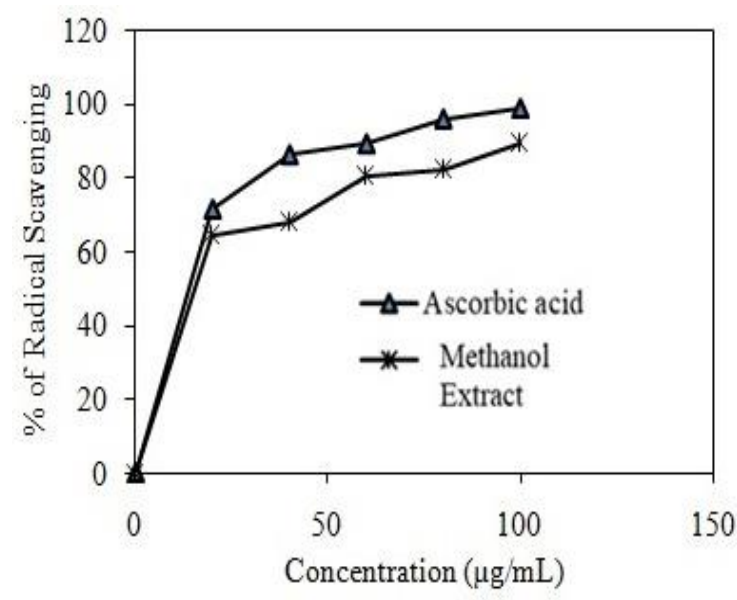

Fig. 1. Percentage of radical scavenging activity of Litsea monopetala methanol extract and ascorbic acid 


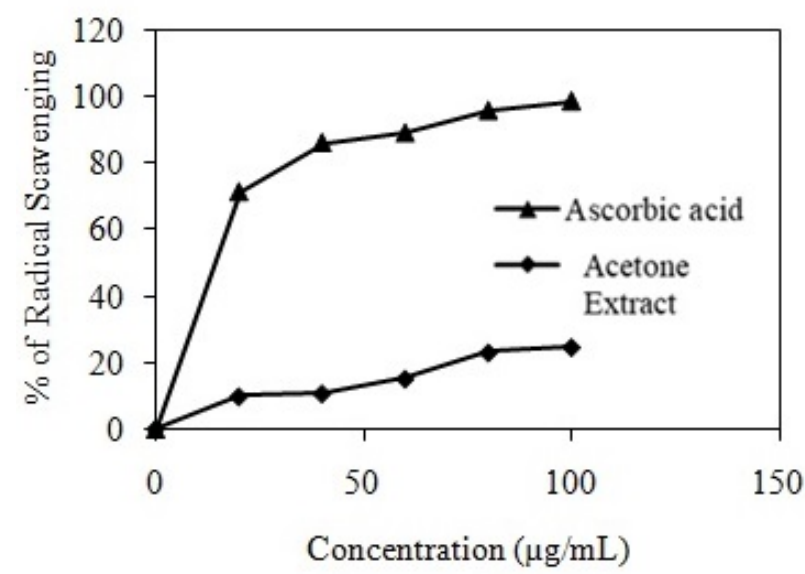

Fig. 2. Percentage of radical scavenging activity of Litsea monopetala acetone extract and ascorbic acid

\section{Total phenolic content (TPC)}

Gallic acid was used as a standard compound for the construction of a calibration curve to estimate the TPC (Fig. 3). From the calibration curve, the total phenolic content was determined in different concentrations of both the methanol and the acetone extracts separately (Table 4). The calculated values (as GAE per g of extract in dry weight) are summarized in Table 5.

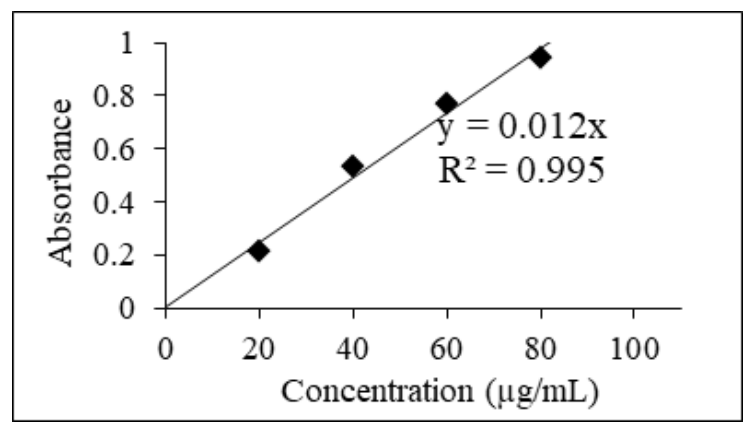

Fig. 3. Calibration curve for gallic acid

Table 4. Absorbance values of leaf extracts of different concentrations of Litsea monopetala for TPC

\begin{tabular}{lccccc}
\hline \multirow{2}{*}{$\begin{array}{c}\text { Plant } \\
\text { extracts }\end{array}$} & \multicolumn{4}{c}{ Absorptions at concentrations $(\boldsymbol{\mu g} / \mathbf{m L})$} \\
\cline { 2 - 6 } & 20 & 40 & 60 & 80 & 100 \\
Acetone & 0.005 & 0.008 & 0.007 & 0.013 & 0.014 \\
Methanol & 0.088 & 0.174 & 0.262 & 0.351 & 0.441 \\
\hline
\end{tabular}

Table 5. Total phenolic content (TPC) of methanol and acetone extracts

\begin{tabular}{ll}
\hline Extract & TPC $(\mathbf{m g ~ G A E} / \mathbf{g})$ \\
\hline Methanol Extract & 360.16 \\
Acetone Extract & 8.98 \\
\hline
\end{tabular}

Total phenolic content was found to be higher in methanol extract (360.14 mg GAE/g) of Litsea monopetala than in acetone extract (8.98 $\mathrm{mg}$ GAE/g). The phenolic compounds help in scavenging the free radicals and thus they possess high antioxidant properties. The extract containing large amounts of polyphenol content are likely to possess greater antioxidant activity due to their free radical scavenging activity. These results were in agreement with the results of phytochemical analysis and antioxidant activity.

\section{Total flavonoid content (TFC)}

The flavonoid of the plant extract in the presence of aluminum chloride forms an acid liable complex, which has an intense yellow fluorescence and thus can be observed under UV spectrophotometer at $510 \mathrm{~nm}$. Aluminum chloride colorimetric method was used to determine TFC in methanol and acetone extracts, taking quercetin as a standard compound. To construct the calibration curve, quercetin was taken as a standard compound. The calibration curve obtained by plotting absorbances at different concentrations of standard quercetin is shown in Fig. 4.

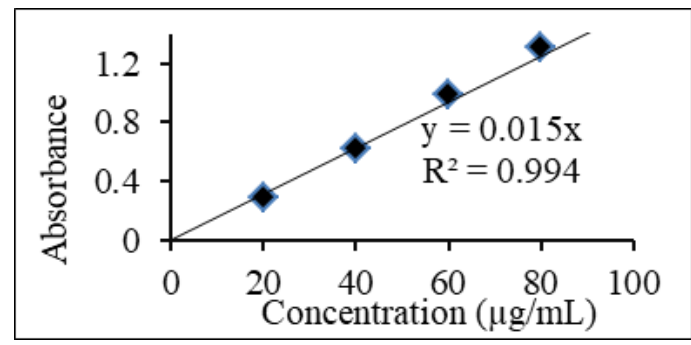

Fig. 4. Calibration curve for quercetin

Using the calibration curve and absorbance values of methanol and acetone extracts at different concentrations $(20,40,60,80$, and $100 \mu \mathrm{g} / \mathrm{mL})$, the TFC values were calculated (Table 6). The TFC values (as mg QE/g) obtained is presented in Table 7. Total flavonoid content was found to be the highest in methanol extract $(27.13 \mathrm{mg}$ $\mathrm{QE} / \mathrm{g})$. In acetone extract, it was found to be $5.48 \mathrm{mg}$ QE/g. Thus, methanol extract of this plant contained large amount of flavonoids. Flavonoid compounds also possess antioxidant properties, due to their free radical scavenging properties. These results are in agreement with the results of phytochemical analysis and antioxidant activity.

Table 6. Absorbance values ofof different concentrations of Litsea monopetala extracts for TFC

\begin{tabular}{lccccc}
\hline Plant & \multicolumn{6}{c}{ Absorptions at concentrations $(\boldsymbol{\mu g} / \mathbf{m L})$} \\
\cline { 2 - 6 } extracts & 20 & 40 & 60 & 80 & 100 \\
Acetone & 0.005 & 0.006 & 0.008 & 0.012 & 0.016 \\
Methanol & 0.011 & 0.019 & 0.028 & 0.037 & 0.048 \\
\hline
\end{tabular}


Table 7. Total flavonoid content (TFC) in ethanol and acetone extracts

\begin{tabular}{lc}
\hline Extract & TFC $(\mathbf{m g ~ Q E} / \mathbf{g})$ \\
\hline Methanol Extract & 27.13 \\
Acetone Extract & 5.48 \\
\hline
\end{tabular}

\section{Antimicrobial activity}

The zone of inhibition (ZOI) was measured for hexane extract, ethyl acetate extract, acetone extract, and methanol extract of the leaves in a fixed concentration of $100 \mathrm{mg} / \mathrm{mL}$. These ZOI values measure the antimicrobial efficacy of these extracts against Gram-positive bacteria, Bacillus subtilis, and Gram negative bacteria, Escherichia coli. The antimicrobial screening data thus obtained is given in Table 8.

Table 8. Antimicrobial activity of different extracts of $L$. monopetala

\begin{tabular}{llcc}
\hline $\begin{array}{l}\text { Plant } \\
\text { extracts in }\end{array}$ & Bacteria & $\begin{array}{c}\text { ZOI of } \\
\text { extracts } \\
(\mathbf{m m})\end{array}$ & $\begin{array}{c}\text { ZOI of } \\
\text { ofloxacin } \\
(\mathbf{m m})\end{array}$ \\
\hline Hexane & E. coli & 0 & 28 \\
& B. subtilis & 10 & 30 \\
Ethyl & E. coli & 16 & 28 \\
acetate & B. subtilis & 18 & 30 \\
& E. coli & 0 & 28 \\
Acetone & B. subtilis & 11 & 30 \\
& E. coli & 0 & 28 \\
Methanol & B subtilis & 0 & 30 \\
\hline
\end{tabular}

The ethyl acetate $(18 \mathrm{~mm})$, hexane $(10 \mathrm{~mm})$, and acetone (11 mm) extract of Litsea monopetala leaf were found to inhibit the growth of Gram positive bacteria Bacillus subtilis. While as, only ethyl acetate $(16 \mathrm{~mm})$ extract of Litsea monopetala leaf was found to be effective against Gram-negative bacteria Escherichia coli. Out of two bacteria used, Bacillus subtilis was more effectively inhibited than E. coli. The reason can be explained by the presence of a unique outer membrane in Gram-negative bacteria, that prevent the extract from penetrating the cell. Gram-positive bacteria, lacking the outer membrane are more likely to be inhibited. These results revealed that the leaf extract of this plant possess antibacterial potential.

\section{CONCLUSIONS}

Phytochemical screening of the methanol extract of Litsea monopeta leaves extract revealed the presence of alkaloids, flavonoids, polyphenols, glycosides, protein, terpenoids, saponins, and carbohydrates. However, in other fractions like ethyl acetate, acetone extracts, alkaloids, flavonoids, and saponin were major phytochemicals. Hexane fraction of the plant showed few phytochemicals.

The methanol extract exhibited good antioxidant property with an $\mathrm{IC}_{50}$ value $(30.74 \mu \mathrm{g} / \mathrm{mL})$, close to the standard ascorbic acid $(21.23 \mu \mathrm{g} / \mathrm{mL})$. Methanol extract has a better antioxidant property than acetone extract. The high $\mathrm{IC}_{50}$ value of the acetone extract $(202.86 \mu \mathrm{g} / \mathrm{mL})$ showed its poor antioxidant efficacy. Methanol extract of Litsea monopetala showed the highest amount of phenolic content (360.14 mg GAE/g extract). Total flavonoids content of methanol extract $(27.13 \mathrm{mg} \mathrm{QE} / \mathrm{g}$ extract) was found to be highest. But acetone extract of Litsea monopetala showed a low value of total flavonoid content (5.48 QE/g extract). These values of TPC and TFC are consistent with the studied antioxidant efficacy of the extracts since methanol extract was found to show high antioxidant activity and acetone extract was found to show low antioxidant activity.

The ethyl acetate extract of Litsea monopetala leaf inhibited Gram-positive bacteria Bacillus subtilis with ZOI value $18 \mathrm{~mm}$, and Gram-negative bacteria $E$. coli with ZOI $16 \mathrm{~mm}$, against. All the above results reflect that the Litsea monopetala, from the Panchthar district of Nepal, is a potential source of several bioactive compounds.

\section{ACKNOWLEDGEMENT}

The authors are heartily thankful to the University Grants Commission, Nepal, for providing financial support, which was very helpful in carrying out and accomplishing this work.

\section{REFERENCES}

Aryal, K. K., Dhimal, M., Pandey, A., Pandey, A.R., Dhungana, R., Khaniya, B.N., Mehta, R.K., Karki, K.B. (2016). Knowledge diversity and healing practices of traditional medicine in Nepal. Kathmandu, Nepal: Nepal Health Research Council, p. 96.9 http://nhrc.gov.np/wpcontent/uploads/2017/06/knowledge-diversity_book1.pdf

Awoyemi, O. K., Ewa, E.E., Abdulkarim I. A., \& Aduloju A. R. (2012). Ethnobotanical assessment of herbal plants in Southwestern Nigeria. Academic Research International, 2(3), 50-57.

Bhandari, P., Gurung, M.B., Subedi, C. K., Chudhary, R. P., Basnet, K. B., Gurung, J., ..., \& Shrestha, K. K. (2020). Traditional use of medicinal plants in the Chyangthapu-Phalaicha biological sub-corridor, Panchthar district, Kangchenjunga Landscape, Nepal. Research Square- Journal of Ethnobiology and Ethnomedicine. https://doi.org/10.21203/rs.3.rs96892/v1 
Cavalieri, S. J., Rankin, I. D., Harbeck, R. J., \& Sautter, R. L. (2005). Manual of antimicrobial susceptibility testing. American Society for Microbiology, 10, 241.

Dhote, K., Dhote, V., \& Khatri, K. (2015). Phytochemical screening and pharmacological activity in Punica granatum. Asian Journal of Pharmaceutical Education and Research, 4(4), 290-297.

Ferdous, Md. R., Ashrafudoulla, Md., Hossain, Md. S., \& Bellah, Sm. F. (2018). Evaluation of antioxidant, analgesic and antidiarrheal activities of methanolic extract of Litsea monopetala (roxb.) leaves. Clinical Pharmacology \& Biopharmaceutics, 7(3), 185 (pp.6).

Gautam, T. (2011). Indigenous uses of some medicinal plants in Panchthar district, Nepal. Nepalese Journal of Biosciences, 1, 125-130.

Gewali, M. B. (2008). Medicinal plants. In S. Awale (Ed.), Aspects of traditional medicine in Nepal (Chapter-2, pp. 31-70). Toyama, Japan: Institute of Natural Medicine, University of Toyama.

Hasan, F., Iqbal, M. A., \& Uddin, S. (2016). Antibacterial and antifungal activity of Litsea monopetala leaves on selected pathogenic strains. European Journal of Medicinal Plants, 12(4), 1-8.

Hasan, H., Azad, S. A., Islam, Z., Rahman, S. M., Islam, R., Rahman, S., \& Rahmatullah, M. (2014). Antihyperglycemic activity of methanolic extract of Litsea monopetala (Roxb.) Pers. leaves. Advances in Natural and Applied Sciences, 8(1), 51-55.

Jamuna, S., Paulsamy, S., \& Karthika, K. (2012). Screening of in vitro antioxidant activity of methanolic leaf and root extracts of hypochaerisradicata L. (Asteraceae). Journal of Applied Pharmaceutical Science, 02(7), 149-154.
Joshi, S., \& Bashyal, S. (2019). Study on the chemical constituents and antibacterial activity of essential oil of Acarus calamus L. rhizomes of Rupendehi district (Nepal). Journal of Institute of Science and Technology, 23(1), 57-60.

Kalita, P., Barman, T. K., Pal, T. K., \& Kalita, R. (2013). Estimation of total flavonoids content (TFC) and antioxidant activities of methanolic whole plant extract of Biophytumsensitivum Linn. Journal of Drug Delivery \& Therapeutics, 3(4), 33-37.

Rajbhandari, M., \& Lindequist, U. (2020). Isolation of flavonoids from Anaphalis busua and their antibacterial activity. Journal of Institute of Science and Technology, 25(1), 1-6.

Ramamurthy, V., Rajeswari, D. M., Gowri, R., Vadivazhagi, M. K., Jayanthi, G., \& Raveendran, S. (2013). Study of the phytochemical analysis and antimicrobial activity of Dodonaeaviscosa. Journal of Pure and Applied Zoology, 1(2), 151-159.

Subba, B., \& Thapa, S. (2018). Analysis of phytoconstituents and biological activities on the selected medicinal plants of Dolakha and Sindhualchowk district of Nepal. Journal of Institute of Science and Technology, 22(2), 140-147.

Wang, Y. S., Wen, Z. Q., Li, B. T., Zhang, H. B., \&Yang, J. H. (2016). Ethnobotany, phytochemistry and pharmacol of the genus Litsea: An update. Journal of Ethnopharmacology, 181, 66-107.

Waterhouse, A. (2012). Folin-ciocalteau micro method for total phenol in wine. https://waterhouse.ucdavis.edu/folin-ciocalteaumicro-method-total-phenol-wine. 